\title{
'What kind of paper do you want from us?': developing genre knowledge in one Kazakhstani university postgraduate school
}

\author{
D. Philip Montgomery \\ Franklin Road Academy, USA
}

Jason Sparks

Nazarbayev University Graduate School of Education, Kazakhstan

Bridget A. Goodman

Nazarbayev University Graduate School of Education, Kazakhstan

\section{Abstract}

Drawing on the Academic Literacies perspectives of Lea and Street and key genre theorists, this mixed-methods case study explored multilingual student experiences of academic literacy practices in one postgraduate social-science school in an English-medium university in Kazakhstan. Two questions guided the research: (1) To what extent and in what ways do students develop genre knowledge in their school EMI contexts? (2) Which pedagogical approaches and strategies do students identify as beneficial in supporting genre knowledge development? The study found students developed genre awareness for research-related literacy practices, involving field-, tenor- and mode-related genre knowledge. The study also found student capacity to apply genre knowledge successfully across a range of text genres. Another finding was that challenge and success in genre knowledge development was a function of the extent of explicit feedback from instructors and peers and explicit assignment expectations. Each of our findings are consistent with the critique and recommendations of Lea and Street $(1998 ; 2006)$ on the importance of a situated approach to developing student academic literacy practice that accounts for the larger institutional contexts and epistemological traditions in which those practices have meaning. These findings have important value for discussions and debates on student academic literacy learning and practice in higher education in Kazakhstan, across Central Asia and in other countries where 
policies for internationalisation and research universities are rapidly transforming higher education literacy practice in the current era of globalisation.

Keywords: academic literacies; systemic functional linguistics; genre; feedback; task guidelines; scaffolding.

\section{Introduction}

Drawing on the academic literacies perspectives of Lea and Street $(1998,2006)$ and genre theorists working in systemic functional linguistics (Hasan, 2009; Martin, 2009), this paper describes a mixed-methods case study inquiry into multilingual student experiences of academic literacy practices in one postgraduate social-science school in an English-medium university in Kazakhstan.

As in so many areas of Kazakhstani life since independence in 1991, the higher education system is facing 'the challenge of moving beyond the Soviet legacy, with all the norms and values embedded in that way of life, and building a uniquely Kazakhstani system of education' (Hartley and Ruby, 2017, p. 2). Key to this new higher education system is its recent European orientation, manifest in Kazakhstan becoming signatory to the Bologna Process in 2010 (Jumakulov et al., 2019). As in other Bologna signatory countries (Phillipson, 2006), recent years in Kazakhstan have witnessed a sharp increase in English as a medium of instruction (EMI) in higher education in order to 'increase competitiveness of students when they leave and position the educational sector as attractive for international students' (Embassy of the Republic of Kazakhstan, (No date)). Important in this policy context is a national trilingual education policy viewing 'Kazakh as the national language, Russian as the language of interethnic communication, and English as the language of successful integration in the global economy' (Nazarbayev, 2007). These changes in policy and practice call for greater student capacity to learn, write and, in the case of PhD students, even publish in English, raising the question of how to develop capacities for English academic literacy in learners and also develop capacity for programs to support that literacy. 
In their influential 1998 article, 'Student writing in Higher Education: an academic literacies approach', Lea and Street called on university educators to look beyond conventional 'skills' teaching models and imagine 'a more encompassing understanding of the nature of student writing within institutional practices, power relations and identities' (p. 158). The authors elaborated the argument in 2006, emphasising the importance of inquiry into 'the processes involved in acquiring appropriate and effective uses of literacy as more complex, dynamic, nuanced, situated, and involving both epistemological issues and social processes, including power relations among people, institutions, and social identities' (p. 369). Central to our inquiry is the explicit academic literacies focus on: (a) 'acts of writing and literacy in subject areas and disciplines' (p. 369); (b) the 'variety and specificity of institutional practices, and students' struggles to make sense of these' (p. 376); and (c) the importance of genre theory in exploring student literacy practices (Russell et al., 2009). Genre scholars argue that academic writing norms are better understood as socially defined (Bruce, 2008), discipline specific (Prior, 2013), flexible and dynamic (Flowerdew, 2013), and immensely important for students to be successful as members of their respective academic and professional discourse communities (Hyland, 2009).

This project was taken up in one Kazakhstani university graduate school seeking to develop student capacity for scholarship and research sufficient to prepare them for careers as academics or other professionals nationally or internationally. The participants were Kazakhstani students coming to the school's Master's and PhD programs primarily from successful professional jobs, and some directly out of their undergraduate programmes. All participants are genuinely multilingual (Kazakh, Russian, English and often other languages) and are highly motivated and capable learners who value what they describe as unique educational opportunities provided by the English-medium graduate school they attend, taught by an international faculty from around the world, and in programme curricula based in models familiar in 'Western' contexts. The impulse for this study was to understand their experiences and perspectives, not because relative student capacity presents a "problem to be solved through additional or remedial support' (Lillis and Scott, 2007, p. 8), but, consistent with the approach described by Lea and Street (1998), this research impulse is based: 
on the premise that in order to understand the nature of academic learning, it is important to investigate the understandings of both academic staff and students about their own literacy practices, without making prior assumptions as to which practices are either appropriate or effective. (p. 158)

In short, drawing on key insights from Lea and Street's model of academic literacies (1998; 2006), and utilizing a conceptual framework for genre, this research is an effort to hear from students themselves about their experiences of engaging in academic literacy practices, including understanding and producing genres, that are often new to them, are critical to their success in their postgraduate programs, and have potential significance to their identities as emerging scholars and professionals during and after their period of program study. Thus, given this research purpose, this mixed-methods case study explores two key questions:

1. To what extent and in what ways do students develop genre knowledge in their school EMl contexts?

2. Which pedagogical approaches and strategies do students identify as beneficial in supporting genre knowledge development?

\section{Key concepts underpinning the inquiry}

\section{Genre, academic literacies, genre knowledge and genre awareness}

Genre is part of a process- and goal-oriented approach to literacy development (Martin, 2009). This concept stands in contrast to a view of language as a set of learned rules and fixed grammatical structures in two ways. First, genre scholars view writing as a social action carried out by language rather than a set of formal features (Tardy, 2009). Second, this understanding of language, stemming from Systemic Functional Linguistics (SFL) (Halliday, 2006; Halliday and Matthiessen, 2014), emphasizes the linguistic choices available in a given social context. Both of these features are consistent with an academic literacies approach (Hyland, 2007; Gee, 2012; Paltridge, 2014). This school of thought works against much of the 
policy and practice of L2 English provision which continues to reflect a deficit model (Lea and Street, 1998; Lillis and Scott, 2007), focused on correcting grammar, spelling and punctuation (Badenhorst et al., 2015) rather than acknowledging the challenges of 'understanding the epistemology and ways of communication of their discipline' (Wingate, 2015, p. 2).

At the nexus of SFL and genre, i.e. the linguistic and the social, are three meta-functions of language which are central to this study: field, tenor and mode. Hasan (2009) elaborates on each of these meta-functions as follows: field is concerned with the social action, goal or purpose one is trying to achieve with language, whether it be to inform, persuade, discuss, or challenge; tenor is concerned with the social relation between those communicating, including their respective roles, status, or social distance; mode is concerned with the medium and channel of communication, including a text's features as determined by the situation, whether it is spoken or written, prepared or extemporaneous, assisting in a material action or constituting an action in or of itself (pp. 178-179).

In this study, we are exploring the extent to which our students feel they have developed their capacity to comprehend and produce an academic text. This ability, as we operationalise it, consists of different skills which can be categorised as elements of field, tenor, or mode. Collectively, this ability is understood in our study as a combination of genre knowledge and genre awareness. Genre knowledge is defined as the ability to produce an academic text in a predictable way, while genre awareness is the ability 'to switch practices between one setting and another, to deploy a repertoire of linguistic practices appropriate to each setting, and to handle the social meanings and identities that each evokes' (Lea and Street, 1998, p. 159).

One essential aspect of having genre awareness is recognizing that academic literacy is a situated practice which changes across purposes, contexts and audiences (Gee, 2012; Correa and Echeverri, 2017). Lea and Street (2006) add specificity to the situatedness of academic writing as social practices associated with such things as 'institutional requirements (e.g., regarding plagiarism, feedback)' and 'variation across individual faculty members' requirements and even individual student assignments' (p. 369). 


\section{Genre, academic literacy development, and pedagogical practice}

Another key aspect of genre knowledge and academic literacy development is the type of pedagogical support provided. In broad terms, genre research supports the view that learners need to be 'apprenticed' and 'scaffolded' (Dreyfus et al., 2016, p. 7) into the ways of producing knowledge for their specific discipline. Recent studies of the pedagogical processes and outcomes of genre-based pedagogies for advancing academic literacy in higher education have focused, for example, on metacognitive scaffolding in doctoral students (Negretti and McGraff, 2018), L2 learner understandings of paraphrasing (Hirvela and Du, 2013), and academic literacy socialisation in L1 teacher education programs (Hedgcock and Lee, 2017). The current study, like the above-mentioned studies, considers students' perceptions of the pedagogical practices which have scaffolded and apprenticed their academic literacy development.

\section{Methods}

This case study (Stake, 1995) uses a sequential explanatory mixed-methods design (Creswell, 2014) to explore the perspectives and experiences of Kazakhstani students from one graduate school of Social Sciences in one Kazakhstani university that uses EMI and provides Academic English courses for the length of each program. Participants were current Master's and PhD students or alumni. For admission to a Master's or PhD program at this institution, students are required to demonstrate a minimum English proficiency at a B2 level on the Common European Framework Reference (CEFR), i.e. 6.5 overall IELTS score. The minimum proficiency requirement to enter the PhD program increases to C1 level (IELTS 7.0). During Master's coursework, students receive Academic English courses face-to-face or online every semester for the duration of their program; $\mathrm{PhD}$ students take Academic English face-to-face for one semester. Two data collection methods were used to explore these questions: first a quantitative survey, followed by a set of five focus group interviews.

\section{Survey}


A Qualtrics online survey tool link was sent via email to students and alumni of the school's Master's and PhD programs ( $\mathrm{N}=364$ ). The final response rate was $32.7 \%$ (60 students, 59 alumni). The survey featured two main sections. For students, section I contained repeated sets of 'can do statements' (ALTE, 2002; Ashton, 2014; Moeller and Fu, 2015; Denies and Janssen, 2016) for reading/research, writing, speaking, and evaluation skills in English, and a 5-point Likert scale was used. For alumni, this section was modified to ask participants to evaluate the importance of each of these activities in their current workplace. Section II asked all participants to evaluate the usefulness of different activities, approaches, and resources for developing their academic communication skills on a 5-point Likert scale, with an open-ended question to add or comment on pedagogical strategies. Like Neff-van Aertselaer (2013), we designed categories and statements based on genres (e.g. blogs, thesis), genre knowledge subskills (e.g. being able to identify and critically evaluate research literature), and strategies (e.g. peer review) identified by the team as typical or expected in the institutional context. Participants were also asked to provide demographic data and general proficiency selfassessment in all languages in their repertoire. The instrument was administered in English. Following an analysis of the survey results, focus group interviews were conducted with current students or alumni of each of the four Master's degree program concentrations in the school.

\section{Focus group interviews}

A semi-structured interview was administered to five sets of Master's students, one set for each of four programme majors and one group of alumni $(n=25$; approximately five in each focus group). The protocol elicited four types of information: 1) experience in learning academic genres prior to enrolment in graduate school; 2) self-assessment of development of proficiency and genre knowledge from the beginning until the end of the program; 3) specific experiences acquiring knowledge of specific genres, including the role of pedagogical supports and strategies; and 4) for alumni, the applications of genre knowledge in the workplace. Probes were added during the interview to focus on themes identified in the quantitative data, e.g. the importance of instructor feedback and the value of peer review. The researchers facilitated the focus group interviews in English, but participants were permitted 
to reply in Russian or Kazakh if they preferred. The preponderance of communication, however, was in English.

\section{Data analysis procedures}

The survey data were loaded into SPSS. Means and standard deviations for each item in section I and II were generated and ranked. Items were then coded as representing field, tenor, mode, and general genre knowledge, acknowledging Hasan's (2009) warning that 'all three parameter choices must be seen together' (p. 187).

Cronbach's alpha was run as a reliability statistic for the scales for students and alumni. For the categories of field, tenor, mode and genre knowledge, the Cronbach's alpha was 0.76 to 0.96 for students, and 0.83 to 0.94 for alumni, which demonstrates the reliability of this scale. Focus group interview data were open coded in NVivo for specific elements of field, tenor and mode that students reported developing, evidence of cognitive and situated genre awareness, and the specific pedagogies and learning strategies that contributed to field, tenor, and mode development. For each research question, quantitative data is presented first, and then discussed with support from the qualitative data.

\section{Findings}

The quantitative surveys and qualitative focus group interviews highlight the important ways students are developing academic genre knowledge and pedagogical approaches and strategies they identify as beneficial in supporting that genre knowledge development.

\section{Genre knowledge}

\section{Field-related genre knowledge}

The strongest reported area of genre knowledge in English was field $(\mathrm{M}=3.80, \mathrm{SD}=0.627)$, those tasks which foreground the purpose of the text. Example field-related survey items 
include 'I can find appropriate and relevant scholarly research articles' and 'I can define and explain terms in my specialty'. The graduate students in this study readily acknowledge the role research texts, and more importantly they as researchers, play in solving problems and sharing knowledge. The most salient themes that arose from the focus groups include the importance of analyzing and synthesizing data, being critical of the texts they read, and developing expertise in order to make evidence-based decisions in their professional lives. Two quotes from students nicely illustrate these sentiments:

(1) [Previously], when we faced a problem, we tried to solve it based on our previous experience. And now when we look at a problem first try to find the literature, we want to try to find if there any kind of evidences, if before we were looking on the internet, what different sites say. But at the moment what we are doing is we are looking research papers, was there any research on this area, so what are their findings, what are their limitations? Now we can do it, [...] now we try to make the decision on the basis of research findings. We just created a research group, where we have seven people in this group, so we are making inquiries, so we are making more structured more systemic, small-scaled action researches, sometimes different kind of research, so it helps us better. So I think we are becoming much better, and it helps a lot.

(2) I am becoming a researcher, I think. Somehow, we are trying to be a researcher and now we know some basics of the research, how to do it and also think we can share it with our colleagues who don't know English, for example. They do not know how to read those first-hand articles ... and maybe we can translate some key points in the article and share with them. Also in our school, for example, we are asked to conduct Action Research or Lesson Study or to do some kind of things, but they don't know how to do it. They just come and start interviewing you, but you [are] like "Where is [the] consent form? Stop! What is the problem of your work?" So, we can share with them our knowledge and skills.

Echoing the experience of many participants, these comments highlight the immediate ways graduate study, in particular academic genre knowledge of research texts, is being applied in the workplace. These alumni are demonstrating what Lea and Street (1998) describe as the capacity to 'deploy a repertoire of linguistic practices appropriate to each setting' (p. 159). 


\section{Mode-related genre knowledge}

Student and alumni textual knowledge, or mode $(M=3.76, S D=0.670)$, was reported as slightly lower than field-related tasks, and manifested itself in participants' recounting of differences between writing, speaking, and reading strategies, as well as the various text types they become familiar with. For example, the survey included mode-related statements like 'I can identify the organisational structure in various types of texts' and 'I can cite sources according to professionally or academically appropriate standards'.

Participants reported knowledge of an impressive amount of text-types. In the focus groups, they mentioned general categories of text using terms like 'scientific writing', 'research articles', and 'academic texts', but they also demonstrated an awareness of distinct text genres and sub-genres. They mentioned writing summaries, reviews, critiques, annotations, policy analyses, reports, literature reviews, responses, proposals, theses, presentations, debates, peer review feedback, emails, blogs, and Moodle forum posts. In recounting and describing these genres, participants discussed the ways their genre knowledge changed in terms of textual features like structure and concision:

(1) One of the challenges that I encounter here, it was structuring my ideas into writing piece that was something I learned through academic English to structure your ideas and then write something, not just flow of what you are thinking. To structure before and then correct it.

(2) I was told that I am using the Russian style of writing, because my introduction was about twenty sentences. I wanted to write everything in introduction, and it wasn't right. And my instructor in Academic English have told me that I have to change my mind and think about topic statement and I should decrease number of words . . .

(3) First, I give the thesis statement, then I try to explain the statement and give an example. Even in Russian it's the same, I come to a certain conclusion. So I try make my writing logical. Before that I just wrote a lot of beautiful words and etc, etc, but no point, no certain point. Now I always try to stick to the point, stick to the point, and I give the point in Russian also. 
(4) When I try to write something formal, formal writing in Russian language, it seems for me even more difficult write in Russian, right now, than in English.

These examples highlight the discourse semantic resources made available by language (Dreyfus et al., 2016, p. 38). In particular, the examples underscore how students come to readjust the academic values they hold toward preparing a text, the form and content of texts, and how these values and resulting practices have lasting effects even in the speakers' L1, Russian.

\section{Tenor-related genre knowledge}

As the lowest reported dimension of genre, the tasks related to tenor $(\mathrm{M}=3.58, \mathrm{SD}=0.765)$ speak to the ways students learn to interact 'academically' with those around them. Interpersonal genre knowledge includes understanding and navigating power dynamics and the multiple roles they need to play as authors, readers, students and colleagues. For example, 'I can identify the intended audience in various types of texts' and 'I can provide my peers constructive, critical feedback about their work'. The focus group interviews revealed that students come to gain awareness of the reader and their expectations, seeing written communication as an interaction rather than a solitary activity. Two participants mention this shift explicitly, especially as an author who writes for the reader to understand:

(1) To change to style, now we care more about a reader, not about what I am writing and how good it is, but to evaluate how well I can deliver my ideas to the reader. Whether they are able to understand me, my points, my evidences.

(2) I hope to become a researcher I hope with this experience I will write more logically comprehensive research papers, so the people will understand the concept of a paper, but people would enjoy the way I write, the way I interact with my readers.

Other participants mentioned that they themselves begin to listen and read more sceptically, something many participants mentioned learning directly from instructor feedback: 
Student: When I hear someone speaking I ask 'Where are they from? What are the sources? Can I believe it? Where can I check it?' Interviewer: Where do you do that? When you are with friends?

Student: Even with friends, I don't believe what they say. Sometimes they say information that is not real, and I don't want to spread this information.

Perhaps the most widely mentioned activity demonstrating interpersonal genre knowledge was peer review. Students gained experience giving feedback, something they were rarely if ever asked to do before. As they became more comfortable and willing to give feedback, some noticed the difficulty of translating that practice into the workplace where this is not a common practice.

(1) As a junior teacher ... I have no right to give feedback.

(2) You see, giving feedback to colleagues who are not prepared to get the feedback, sometimes it was difficult. Because some people accepted as critique and some people don't like to be criticised or something. They don't see that criticism as the way I want to help them, they think the way I want to criticise them. Probably we are not learned, we don't give feedbacks very well, starting with the good points, I think you should do this, probably we need to work on this skill, how to give good feedback, and then our colleagues will feel comfortable themselves.

Most notably, the two comments above demonstrate how upon encountering resistance to peer feedback from colleagues in the workplace, students employ an educational strategy to the problem: if we work on the skill by explicitly defining and practising what it means to give good feedback, then it will improve. It is also heartening to see the students take on this role of ambassador to share the lessons from the graduate school to their workplaces, as this and other examples demonstrated.

We turn now from the previous discussion of what linguistic and semiotic resources the students gain in an EMI graduate program to the pedagogical approaches, tasks and strategies that students identify as most clearly responsible for developing those resources. 


\section{Developing situated genre awareness}

As described above, genre awareness describes the 'rhetorical flexibility necessary for adapting socio-cognitive genre knowledge to ever-evolving contexts' (Johns, 2008, p. 238), highlighting the 'situated' focus of the academic literacies model concerned with the 'institutional nature of what counts as knowledge in any particular academic context' (Lea and Street, 2006, p. 369). This contextual dimension is further clarified by Correa and Echeverri (2017), who emphasise the 'lexical, grammatical, and textual features' of academic communication relevant to any given context, (p. 45). The qualitative data below demonstrate student development of this situated genre awareness.

Several students and alumni described their experiences of success or difficulty with surfacelevel textual features like structure and formatting writing assignments in relation to the four communicative skills of reading, writing, listening, and speaking. Here, academic is understood by participants as specific genre features of academic communication as compared to conversational or general language use, suggesting an emergent recognition of ways language use responds to different contextual demands. As one student noted:

I was struggling with writing skills, because if to compare writing skills before and after, before I had more conversational style of writing but coming here it is more getting academic.

Similarly, other participants described progress in certain skills during their program learning:

(1) Reading really help[ed] to improve writing, you get familiar with different sentence structure with new words. And with reading materials I managed to improve my writing skills.

(2) Interviewer: What other things can you do better . . . that you noticed you can do better in using language ... that you know you now feel confidence, competence in? Things like, oh, I can do this better ...

Student: I am really good at writing and reading, my reading is really good at IELTS, but I cannot say the same thing about my speaking. 
Interviewer: Are you doing things in language, you are doing better or differently? Student: You mean four skills?

Finally, some students and alumni pointed to the importance of structure in academic writing as a tool or strategy that helps them meet the interpreted communication needs of their postgraduate program context and the discipline they are beginning to understand their work within. These examples show how they begin to see structure as noun and a verb by linking it directly to the process and product of writing:

(1) But what I know now is a structure of writing, it is not very difficult for me now to write an essay [for a class assignment] in a short period of time.

(2) When you know the structure, when you know how to write [for class assignments], I can apply this knowledge into [my Master's thesis] research writing.

These examples suggest an emerging genre awareness that is further refined with more practice and exposure to academic genres. The students learn and use the genre features they associated with course essay assignment writing and describe being able to apply it to the Master's thesis genre. As students learn the ways texts must adapt according to their context, purpose and audience, they demonstrate emergent, situated awareness in numerous ways. Instead of referring to surface features, respondents differentiate between texts by the way language is used, often emphasizing the purpose that the text is trying to achieve (representing awareness of field), or the person for whom the author is writing (representing that of tenor). One student described her assignments like this:

I think some of the assignments are really like puzzle pieces, which we know should connect into one big picture of our thesis. Because for example the research proposal we did previously and article evaluations, they all can be connected into the skills that we need to for thesis production.

It seems that for her, 'skills' are not reading, writing, listening and speaking, but rather the multi-step process of proposing, evaluating, and producing a thesis, i.e. a text socially defined by the faculty. Not only that, she demonstrates a metacognitive awareness of how her 
learning is intentionally scaffolded. For many respondents, academic texts come to be defined by their communicative purpose, often with a specific audience in mind:

Our professor asked us to interview staff members [of a childcare facility] to identify some problems and suggest ways of solving these problems. And I am proud of those solutions to the problems that I gave, because they can really be helpful.

While this awareness was often reported as something that students gained confidence in, respondents also reported not always feeling comfortable in their roles as critical evaluators and problem solvers, especially toward expert authors and scholars:

Actually, I had an experience, when we were supposed to write not an annotation like in another class, but an article critique and I wrote more like article annotation. And one of the professors told me "You need to be more critical when you are beginning the article, you need to express yourself". But I was thinking like: "Who am I to judge this great researcher, to judge his great piece of writing? Who am I?" [I realised] I was trying to be more like polite when writing the article critique. So for the next article critique I got my highest mark, but it was so hard. So I think it really depends on professor, how he wants it, in what way.

One common hurdle to the development of situated genre knowledge appears to be gaining awareness of individual professor expectations, as the professor is the principal audience member in most student writing. Nevertheless, many participants reflected confidence in the role they were developing into, as critics, scholars, and researchers, most notably in the ways they interacted with their peers:

When we were working on thesis writing course, when we sent each other individual . .. how is it called? . . . parts of the thesis ... we tried to help peer review, because we read the whole thing that was sent to us and we tried to give advice not only in terms of grammar and such things, but also in terms of the parts that need to be corrected as a researcher. 
These last two examples speak to the quantitative data that suggest that students feel least confident in activities demanding an interpersonal awareness in English. Students, especially those learning English as an additional language, likely begin like that student asking, 'Who am I to judge?' professional scholars. Here we see participants reflecting on issues of 'meaning making, identity, power, and authority' (Lea and Street, 2006, p. 369), issues emerging in experience of the 'variety and specificity of institutional practices' of the school, and their 'struggles to make sense of these' (Lea and Street, 2006, p. 376).

\section{Pedagogical approaches}

The survey included 32 items for students (see Table 1) to evaluate the usefulness of specific teaching and learning activities. These were presented in the following groups: general activities, reading and writing, speaking and listening. The items include a range of activities that reflect widely discussed pedagogical principles: group tasks and individual tasks, practice work and project work, informal and formal speaking, informal and formal writing, informal (formative) and formal (summative) feedback, using a rubric, instructor and peer feedback, giving and receiving feedback, professional and student example texts, reflection on learning, writing as a process of revision, translating new words, and using L1 in learning L2. On a scale of $1-5$, from 1 being not helpful at all and 5 being extremely helpful, all activities were evaluated as moderately, very, or extremely helpful $(M>3.00)$.

\section{Table 1.}

Helpful teaching activities ranked.

\begin{tabular}{lllll}
\hline No & Descriptor & $\mathrm{N}$ & Mean $^{\mathrm{a}}$ & $\mathrm{SD}$ \\
\hline Extremely helpful $(\mathrm{M}>4.25)$ & & & \\
\hline $1 \quad$ & Receiving instructor feedback on written work & 60 & 4.47 & .812 \\
2 & $\begin{array}{l}\text { Receiving informal, formative feedback (comments on } \\
\text { ungraded work) }\end{array}$ & 58 & 4.31 & .922 \\
$3 \quad \begin{array}{l}\text { Completing formal writing assignments (course papers, } \\
\text { thesis project) }\end{array}$ & 60 & 4.27 & .821 \\
Very helpful (M=3.50 4.25) & & & &
\end{tabular}


$4 \quad$ Speaking in class discussions

$5 \quad$ Using a rubric to evaluate writing and speaking tasks

6 Individual practice tasks (homework or in class)

7 Receiving formal, summative feedback (comments on graded work)

$8 \quad$ Listening to peers in class discussions

9 Speaking in formal presentations

10 Reflecting on my own work or progress in a course

11 Individual research projects

12 Asking and answering questions in a formal presentation (debate, poster, Q\&A)

13 Analyzing published research and textbooks as examples

14 Writing and revising multiple drafts of an assignment

15 Having consultations with instructors or writing center tutors

16 Completing informal writing assignments (blogs, outlining, planning, reflections)

17 Listening and notetaking in lecture or guest speaker settings

18 Giving informal presentations (reporting to the group)

19 Having informal chats with instructors

20 Research projects in a collaborative group setting

21 Observing others communicate in academic settings (e.g. asking questions, giving presentations)

22 Analyzing sample student assignments and theses as examples

23 Giving peer feedback on written work

24 Having informal chats with peers

25 Receiving peer feedback on written work

26 Group practice tasks (homework or in class)

27 Completing semester-long projects or portfolios $\begin{array}{lll}59 & 4.24 & .773\end{array}$

$\begin{array}{lll}60 & 4.20 & .879\end{array}$

$\begin{array}{lll}59 & 4.19 & .730\end{array}$

$\begin{array}{lll}60 & 4.17 & .977\end{array}$

$\begin{array}{lll}59 & 4.15 & .827\end{array}$

$\begin{array}{lll}59 & 4.08 & .726\end{array}$

$\begin{array}{lll}60 & 4.08 & .809\end{array}$

$\begin{array}{lll}59 & 4.07 & .828\end{array}$

$\begin{array}{lll}60 & 4.07 & .710\end{array}$

$\begin{array}{lll}58 & 4.03 & .837\end{array}$

$\begin{array}{lll}60 & 4.03 & .956\end{array}$

$\begin{array}{lll}57 & 3.98 & .973\end{array}$

60

$3.97 \quad .780$

60

$3.93 \quad 821$

60

$3.93 \quad 821$

56

$3.89 \quad .947$

$\begin{array}{lll}60 & 3.88 & 1.027\end{array}$

60

$3.83 \quad .905$

58

$3.81 \quad 1.034$

58

$3.79 \quad 987$

$\begin{array}{lll}59 & 3.78 & .892\end{array}$

57

$3.77 \quad 1.018$

60

$3.73 \quad .954$

59 
Moderately helpful ( $M=2.75 \sim 3.49)$

28 Preparing for and taking written quizzes or tests

$59 \quad 3.46 \quad 1.134$

29 Receiving instructor explanations or feedback in Kazakh

$48 \quad 3.35 \quad 1.082$ or Russian

30 Using Kazakh or Russian with my peers to complete

$\begin{array}{lll}60 & 3.32 & 1.033\end{array}$ group tasks

31 Translating new words

$58 \quad 3.26 \quad .983$

32 Using non-English language sources in English research

$\begin{array}{lll}58 & 3.03 & 1.042\end{array}$ writing

a Scale: $5=$ extremely helpful, $1=$ not helpful at all

As none of the tasks were viewed as only slightly helpful or totally unhelpful, this may suggest that it is the variety of teaching and learning activities which is important. Students emphasise several important ways that help them develop as competent academic communicators, as the following data and examples illustrate.

\section{Feedback and interaction}

Students highly value detailed, descriptive instructor feedback, ranking instructor feedback $(\mathrm{M}=4.47)$ on written work as the single most helpful learning activity in the survey and informal, formative feedback $(\mathrm{M}=4.31)$ on ungraded work as the second. Formal summative comments $(M=4.17)$ are also very helpful, yet slightly less than informal, formative feedback $(\mathrm{M}=4.31)$. One student explained it this way:

Feedback was very important even you get high mark, even you get low mark, you should know why you get this mark it is really important. Giving just numbers is not so important like giving real things, areas feedback with errors...

Peer feedback in general is seen as somewhat less helpful than instructor feedback, although giving $(M=3.79)$ and receiving $(M=3.77)$ feedback are nearly equally very helpful. While peer review and instructor feedback were seen as highly valuable interactions, interestingly, individual tasks such as practice $(M=4.19)$ or research projects $(M=4.07)$ are considered 
slightly more helpful than group practice $(M=3.73)$ or collaborative projects $(M=3.88)$.

Feedback itself is a staged goal-oriented social process with the opportunity for students and instructors to engage in negotiated construction of shared meaning of appropriate communication (Dreyfus et al., 2016), which students see as essential to building their own genre knowledge.

\section{Clear task guidelines and expectations}

Participants voiced considerable agreement that sample texts $(M=3.03)$ and rubrics $(M=4.20)$ were quite helpful in communicating guidelines and expectations. This is unsurprising as students are unfamiliar with target genres like literature reviews or critical responses and face challenges interpreting task prompts that ask them to 'engage the literature' or 'critically evaluate sources'. Several participants mentioned adopting these practices in their own teaching, and in one particularly memorable instance, a student recalls the frustration felt when they were given an assignment without those detailed guidelines they had become accustomed to receiving:

When our teacher assigned us to write an academic paper, we didn't know what kind of paper we should write, whether it should be literature review, whether it could contain empirical study, whether it should be based on article review. So it was very unclear, so we didn't know what to write basically we wrote what we understand. It was really strange for some reason. I think some of our colleagues can recall these moments when we asked, what kind of paper do you want from us?

This remarkable quote echoes the concerns of students reported by Lea and Street (1998) that 'many of the difficulties they experienced with writing arose from the conflicting and contrasting requirements for writing on different courses and from the fact that these requirements were frequently left implicit' (Lea and Street, 1998, pp. $161-162)$. This point is elaborated by Tardy (2009), who describes the process of building genre knowledge as the experience of numerous textual and oral interactions guiding the learner toward capacity for making judgements on situationally-appropriate academic communication. This student's 
agentive plea for the instructor to meet them halfway as they struggle through this ambiguity underscores the highly social nature of both genre knowledge and the process of building it.

\section{Scaffolded instruction}

The survey showed that practice activities $(M=4.19)$ with formative feedback $(M=4.31)$, leading to semester-long projects $(M=3.88)$ including research projects $(M=4.07)$ and the thesis $(M=4.27)$ were highly valued teaching activities. Students were quick to point out the benefit of assignments and skills fitting together 'like a big puzzle', aiding the student to gradually internalise genre knowledge.

It was step by step, we started from beginner part and the last task was very big, it was assumed to include all things we learned. Of course, we were provided with the structures, previously, example, structure in what way, then the task, when you are trained, like exercises, then after you apply it, you personalise it. This is I think very important when you personalise when you write something that is about you, not I mean about you personally, but about your study, let's say research.

The fact that students lament the lack of purposeful, systematic scaffolding of tasks to develop skills in their prior educational experiences ('Nobody taught me how to write academically in Russian language') makes this is all the more valuable when they do receive it.

\section{Conclusions}

In the end, we find that genre knowledge development has less to do with surface features of texts, and more with the social environment in which they learn and write. What students learn and how they learn it are tied directly to the relationship students have with their instructors and peers, and to their awareness of their audience, context and purpose in writing. In particular, students demonstrated awareness that genre knowledge in academic English consists of knowledge of similarities and differences in structures of different types of 
texts (i.e. mode) and the overall purpose of a text (i.e. field), knowledge which goes beyond construction of grammatically correct individual sentences and moves into the discourse level. Here, students reported a capacity for applying genre knowledge to different text genres in ways consistent with what Lea and Street (2006) describe as the 'switching, transformation, and the changing of meanings and representations from one genre and mode to another' ( $p$. 372) for academic literacies development.

We also saw important challenges for students in developing awareness of and competence in writing for a particular audience (i.e. tenor), something connected to unclear or diverse expectations from individual professors, echoing findings from Lea and Street (1998) that it is frequently very difficult for students to 'read off' from any such context what might be the specific academic writing requirements' (p. 161). This challenge was also connected with the perception that professors were at times asking students to position themselves in ways aimed towards the identity they should have as researchers upon graduation, but it was an identity they were still growing into.

It is clear from the survey and focus group data that challenge and success in genre knowledge development was largely a function of explicit feedback from instructors and peers. In other words, the lack of explicit feedback or guidelines for completing academic writing tasks was a challenge for students, and explicit feedback and guidelines from instructors and peers facilitated genre knowledge. This suggests that professors across disciplines need to be encouraged to provide such feedback and structure to Kazakhstani students. Alternatively, lecturers need to communicate to academic writing instructors and tutors the disciplinary specific genres and modes of communication used within their field so they can provide such feedback to students.

We will conclude here by considering these findings in relation to three key points from Lea and Street's seminal 1998 article that has instigated much discussion and debate in higher education. Firstly, it is clear from our findings that understanding student success in literacy practices needs to move beyond focus on the 'students themselves' and consider 'the interaction of the student with institutional practices' (p. 170); in other words, what is needed is a more situated approach that more productively accounts for the larger institutional context 
in which those literacy practices have meaning. Academic literacy capacities based in genre knowledge and genre awareness developed in 'complex, dynamic, nuanced, [and] situated' (p. 369) social processes experienced within this particular school context.

Secondly, and following on the point above, our findings provide insight into the importance of a more situated approach that accounts for the ways students develop capacity to successfully 'switch' between 'disciplines, course units, modules and tutors' (p. 162). Interestingly, we saw students probably outpace some of their course instructors in realising, and strategically responding to, the 'ways different assumptions about the nature of writing, related to different epistemological presuppositions about the nature of academic knowledge and learning, are being brought to bear, often implicitly, on the specific writing requirements of their assignments' (p. 162). There is much for university faculty and programme directors to learn from these student insights, and it seems clear that facilitating student literacy learning and practice is significantly based in institutional capacity to reduce the 'conflicting and contrasting requirements for writing' (p. 161) across courses and programmes and making explicit those requirements often left implicit.

Lastly, we wholeheartedly agree that 'an academic literacies perspective may provide [...] a fruitful area for research and for teacher education in higher education in the coming years' (p. 171). This certainly holds true in Kazakhstan and across Central Asia, where higher education is dramatically transforming on a trajectory that is, on the one hand, largely familiar to us (the Bologna Process), but on the other hand, uncertain as the 'dominance of western discourse on internationalisation has begun to be challenged as other countries emerge as key players' (Jones and de Wit, 2012, p. 46). In this evolving context of internationalisation, and more specifically as academic research expands as a university priority across Central Asia as elsewhere (Altbach, et al., 2018), policy and practice for student research capacity will highlight new research-related literacy practices. Here, research addressing such topics as 'the range of genres, modes, shifts, transformations, representations, meaning-making processes, and identities involved in academic learning within and across academic contexts' (Lea and Street, 2006, p. 376) will be key, both for understanding and responding to emerging trends facing educators and learners in the current era. 


\section{References}

Altbach, P., Reisberg, L., Salmi, J. and Froumin, I. (eds.) (2018) Accelerated universities: ideas and money combine to build academic excellence. Boston, MA: Brill.

Ashton, K. (2014) 'Using self-assessment to compare learners' reading proficiency in a multilingual assessment framework', System, 42, pp. 105-119.

Association of Language Testers in Europe [ALTE] (2002) The ALTE can do project. Available at: www.cambridgeenglish.org.

Badenhorst, C., Moloney, C., Rosales, J., Dyer, J. and Ru, L. (2015) 'Beyond deficit: graduate student research-writing pedagogies', Teaching in Higher Education, 20(1), pp. 1-11. http://dx.doi.org/10.1080/13562517.2014.945160

Bruce, I. (2008) Academic writing and genre: a systematic analysis. London: Continuum.

Correa, D. and Echeverri, S. (2017) 'Using a systemic functional genre-based approach to promote a situated view of academic writing among EFL pre-service teachers', HOW Journal, 24(1), pp. 44-62. Available at: http://doi.org/10.19183/how.24.1.303

Creswell, J. (2014) Educational research: planning, conducting, and evaluating quantitative and qualitative research. (4 ${ }^{\text {th }}$ Ed.). Harlow, UK: Pearson Education.

Denies, K. and Janssen, R. (2016) 'Country and gender differences in the functioning of CEFR-based can-do statements as a tool for self-assessing English proficiency', Language Assessment Quarterly, 13(3), pp. 251-276. https://doi.org/10.1080/15434303.2016.1212055

Dreyfus, S. J., Humphrey, S., Mahboob, A. and Martin, J. R. (2016) Genre pedagogy in higher education: the SLATE project. London: Palgrave Macmillan. 
Embassy of the Republic of Kazakhstan. (No date) 100 concrete steps to implement the 5 institutional reforms [Online]. Available at: https://www.kazakhembus.com/content/100concrete-steps-implement-5-institutional-reforms

Flowerdew, J. (2013) Academic discourse. London: Routledge.

Gee, J. P. (2012) Situated language and learning: a critique of traditional schooling. London: Routledge.

Halliday \& Matthiesen (2014) The development of language: functional perspectives on species and individuals. London: Continuum.

Halliday, M. A. K. (2006) 'On grammar as the driving force from primary to higher-order consciousness', in Williams, G. and Lukin, A. (eds.) The development of language: functional perspectives on species and individuals. London: Continuum, pp. 15-44.

Hartley, M. and Ruby, A. (2017) 'Higher education reform in a new nation state: Kazakhstan's experience', in Hartley, M. and Ruby, A. (eds.) Higher education reform and development: the case of Kazakhstan. Cambridge, UK: Cambridge University Press, pp. 1-12.

Hasan, R. (2009) 'The place of context in a systemic functional model', in Halliday, M. A. K. and Webster, J. (eds.) Continuum companion to systemic functional linguistics. London: Continuum, pp. 166-189.

Hedgcock, J. S. and Lee, H. (2017) 'An exploratory study of academic literacy socialisation: building genre awareness in a teacher education program', Journal of English for Academic Purposes, 26, pp. 17-28. Available at: https://doi.org/10.1016/j.jeap.2017.01.004 
Hirvela, A. and Du, Q. (2013) '“Why am I paraphrasing?”: undergraduate ESL writers' engagement with source-based academic writing and reading', Journal of English for Academic Purposes, 12(2), pp. 87-98. Available at: https://doi.org/10.1016/j.jeap.2012.11.005

Hyland, K. (2007) 'Genre pedagogy: language, literacy, and L2 writing instruction', Journal of Second Language Writing, 16, pp. 148-164.

Hyland, K. (2009) Academic discourse: English in a global context. London: Continuum.

Johns, A. M. (2008) 'Genre awareness for the novice academic student: an ongoing quest', Language Teaching, 41(2), pp. 237-252. Available at: https://doi.org/10.1017/S0261444807004892

Jones, E. and de Wit, H. (2012) 'Globalization of internationalization: thematic and regional reflections on a traditional concept', AUDEM: The International Journal of Higher Education and Democracy, 3(1), pp. 35-54.

Jumakulov, Z., Ashirbekov, A., Sparks, J., and Sagintayeva, A. (2019) 'Internationalizing research in Kazakhstan higher education: a case study of Kazakhstan's state program of industrial innovative development 2015 to 2019. Journal of Studies in International Education, 23(2), pp. 234-247.

Lea, M. R. and Street, B. V. (1998) 'Student writing in higher education: an academic literacies approach', Studies in Higher Education, 23(2), pp. 157-172.

Lea, M. R. and Street, B. V. (2006) 'The "Academic Literacies" model: theory and applications', Theory into Practice, 45(4), pp. 368-377. Available at: https://doi.org/10.1207/s15430421tip4504 11

Lillis, T. and Scott, M. (2007) 'Defining academic literacies research: issues of epistemology, ideology and strategy', Journal of Applied Linguistics, 4(1), pp. 5-32. 
Martin, J. R. (2009) 'Genre and language learning: a social semiotic perspective', Linguistics and Education, 20(1), pp. 10-21. Available at: https://doi.org/10.1016/..linged.2009.01.003

Moeller, A. J. and Yu, F. (2015) 'NCSSFL-ACTFL can-do statements: an effective tool for improving language learning within and outside the classroom', Dimension 2015, pp. 50-69. Available at: http://www.scolt.org/wp-content/uploads/2019/08/Dimension2015 FINAL 4-29.pdf

Nazarbayev, N. (2007) New Kazakhstan in a new world: address 2007. Available at: http://mfa.gov.kz/en/consuldubai/content-view/kazakstan-respublikasyny-prezidentinnazarbaevty-kazakstan-halkyna-zoldauy-2007-zylgy-28-akpan

Neff-van Aertselaer, J. A. (2013) 'Contextualizing EFL argumentation writing practices within the Common European Framework descriptors', Journal of Second Language Writing, 22, pp 198-209.

Negretti, R. and McGrath, L. (2018) 'Scaffolding genre knowledge and metacognition: insights from an L2 doctoral research writing course' Journal of Second Language Writing, 40, pp 12-31. Available at: https://doi.org/10.1016/j.jslw.2017.12.002

Paltridge, B. (2014) 'Genre and second-language academic writing', Language Teaching, 47(3), pp. 303-318. Available at: https://doi.org/10.1017/S0261444814000068

Phillipson, R. (2006) 'English: a cuckoo in the European higher education nest of languages?', European Journal of English Studies, 10(1), pp. 13-32.

Prior, P. (2013) Writing/disciplinarity: a sociohistoric account of literate activity in the academy. Hoboken, NJ: Routledge. 
Russell, D. R., Lea, M., Parker, J., Street, B. and Donahue, T. (2009) 'Exploring notions of genre in "academic literacies" and "writing across the curriculum": approaches across countries and contexts', in Bazerman, C., Bonini, A. and Figueiredo, D. (eds) Genre in a changing world: perspectives on writing. Fort Collins, CO: The WAC Clearinghouse and Parlor Press, pp. 395-423.

Stake, R. E. (1995) The art of case study research. Thousand Oaks, CA: Sage Publications.

Swales, J. M. (2004) Research genres: explorations and applications. Cambridge, UK: Cambridge University Press.

Tardy, C. M. (2009) Building genre knowledge (second language writing). Anderson, SC: Parlor Press.

Wingate, U. (2015) Academic literacy and student diversity: the case for inclusive practice. Bristol: Multilingual Matters.

\section{Author Details}

D. Philip Montgomery was Instructor at Nazarbayev University Graduate School of Education from 2014 to 2019, and currently teaches at Franklin Road Academy, USA.

Jason Sparks is Associate Professor and Vice Dean at Nazarbayev University Graduate School of Education.

Bridget Goodman is Assistant Professor and Director of the M.A. in Multilingual Education program at Nazarbayev University Graduate School of Education. 